\title{
DeVeloping A ConVERgenCE Methodology BETWEEN ENGINEERING TECHNOLOGY AND FASHION DESIGN EDUCATION
}

\author{
Hyunseung Lee \\ Modular Fashion Platform Research Centre, Kookmin University, \\ Seoul City, South Korea
}

\begin{abstract}
This study proposed a convergence design process comprising the creativity of fashion design and the technology of engineering for fashion design education. It incorporated the concept of the convergence tendency in modern industry. The primary study combined an engineering design process that promoted engineering thinking and a fashion design process that promoted creative thinking to create a practice model that was developed and tested in a 10-week workshop. The result showed the need for refining the practice model to encourage in-depth cooperation. Therefore, a second practice model composed of an interaction design process and a fashion design method was investigated to promote students' interconnected thinking and force iterative processing. To verify the usability of the refined practice model, a second workshop using the latest model was conducted over 15 weeks. A tendency for convergence, where knowledge and techniques were shared among designers and engineers to address problems, was observed. The functionality of the four prototypes that were developed based on the idea of setting and solving a design issue was also embodied. It is expected that the processes and results can be utilized as a basis for the development of design methodologies and education programs in various design areas, including fashion, in this era of converged industries.
\end{abstract}

\section{KEYWORDS}

Cooperative practice, Design process, Fashion education, Convergence design education

\section{INTRODUCTION}

In the concept of convergence, heterogeneous components come together in one process. In modern industry convergence is a way of breaking out of the existing frameworks and creating new products and services [1]. Trends in convergence have tended towards combining various technologies with IT since the mid-2000s [2], [3]. For instance, IoT technology embodied in global IT enterprises and diverse academic areas has been applied to fashion items including glasses and watches called wearable technology [4], [5].

The focus of this study's educational research and development (hereunder, R\&D) is on functions that should be useful for customers and embodied in the form of fashion items. It is expected that this trend will accelerate with advances in virtual and augmented reality technologies and expanded markets [6], [7], [8], [9], [10].

Education in convergence is essential for taking the lead in modern industries, particularly in fashion design. To this end, it is vital to develop methodologies for conducting design processes that promote cooperation among different areas of expertise between Design and Engineering through systematic assignment division. Such methodologies should induce a convergence of knowledge, technology, and experience among the different areas, as well as a conception of creative ideas so that professionals in different fields, such as fashion and IT, can derive one integrated product. Fashion items, especially garments, which are worn could be a suitable medium to combine with engineering technologies to provide further functionality, and the fusion 
could be key for expanding the traditional industry boundaries and roles of fashion. In order to achieve this substantial expansion of fashion, designers need to be prepared to have flexible, alternative perspectives and practical expertise on the convergence of technologies through interactive practices with engineering experts by sharing their expertise with each other.However, in general, designers in convergence $\mathrm{R} \& \mathrm{D}$ tend to take a passive role in the actual development tasks, after the initial ideation and fashion (garment) platform design has been conceived [11]. As a result, engineers then manage the overall development tasks focusing on rational and efficient completion of the digital systems and their integration into the platforms. The drawbacks from the fashion perspective are as follows: first, inner-structures of the platforms are modified to make space for systems while disregarding the aesthetics of the construction; second, system devices are dispersed throughout the platform without in-depth consideration for the structural interaction between wearers' bodies and the platforms, with negative effects on appearance, wearability, comfort, and activity level when the garment is worn.It appears that these negative results are due to a lack of cooperation on convergence projects that emerges because of the strict role divisions in engineering and fashion majors. Of course, it would be ideal to provide design majors with engineering subjects for the ultimate convergence $R \& D$ project, but this is not realistic in academia. In convergence fashion product development (CFPD) designers should not only play a role in the exterior design of the product, but also deal with the concepts and mechanisms of its functions, and manage the aesthetics as well as the range of applied technologies in the R\&D.

In order to achieve fully converged and shared expertise between engineering and fashion majors, an institutional strategy encouraging flexibility and inter-connected roles that promote students to cross the boundaries of their majors is needed. It is expected that designers could perform indepth studies of the product's exterior and structural designs, and explore the functionalities of their ideas in an effort to understand device mechanisms. This could be achieved through interconnected role-playing with engineers during primary investigations of the technological components, such as micro-controllers and sensors. At the same time, engineers could also be led to promote flexible thinking when selecting components, connection methods between devices, and making circuit boards that can be washed, thus devising platforms and system maintenance that exceeds the usual standards of their majors. In inter-connected cooperation (role-playing), instructors and lecturers' roles would be to significantly mediate students' stepwise processing and force self-evaluation of their work and investigation of any unfamiliar expertise of the other major in order to prevent one-sided process tasking in each processes of practices.

Therefore, in this study, a convergence practice model for fashion prototype development with balanced and inter-connected cooperation between design and engineering majors was conducted to investigate the realistic possibilities of holding classes focusing on engineering subjects such as electronics, software, and mechanics. This study aimed to develop an effective methodology for CFPD R\&D practices that could encourage students' inter-connected processing and verify the usability and adaptability of the methodology in fashion design education.

This study comprised the following steps:

First, a primary study of the CFDP practice model focused on the integration of the engineering design process (EDP) and the fashion design process (FDP) [12], [13].

Second, in order to promote a convergence-based thinking process for garment and system elements, and inter-connected practice in the development of convergence fashion product design, the processes of interaction and fashion designs were combined as a CFPD methodology. 
Third, a second convergence workshop was conducted using the revised methodology after the CFPD was tested. The goal was to verify the effectiveness of the convergence product development methodology.

\section{LITERATURE REVIEW}

\subsection{The EDP in this study}

From the 1960s onward, operation research (OR) and system engineering (SE) which were the initial concepts comprising EDP have been used in the private sector. As the engineering industry grew in the 1960s, product design became more complicated and diversified. As a result, the necessity for scientific approaches to design methodologies was emphasized. Accordingly, systematic approaches such as OR and SE were required in the design field as well, although it was challenging to apply engineering problem-solving methodologies directly to design [14], [15], [16]. In the 1960s, researchers such as J. C. Jones, C. Alexander, and B. Archer facilitated research on design methodologies, presenting the first-generation design process models of the linear hierarchy - "analyzing problems," "synthesizing problems," and "evaluating solutions" and going beyond the existing black-box models in which the relation between design work and products was vague [16]. In the analysis step, a quantitative investigation of markets, consumers, and products is conducted. In the synthesizing stage, designs and products are developed as reflected the findings of the analysis stage. In the evaluation stage, results from the two previous stages are assessed and corrective measures developed. While the first-generation EDPs developed by Jones, Alexander, and Archer prefer a scientific approach to design problems, $\mathrm{H}$. Ritel viewed design problems as complicated, pluralized, and "ill-defined," as the industrial society advanced, and the markets changed accordingly [16].

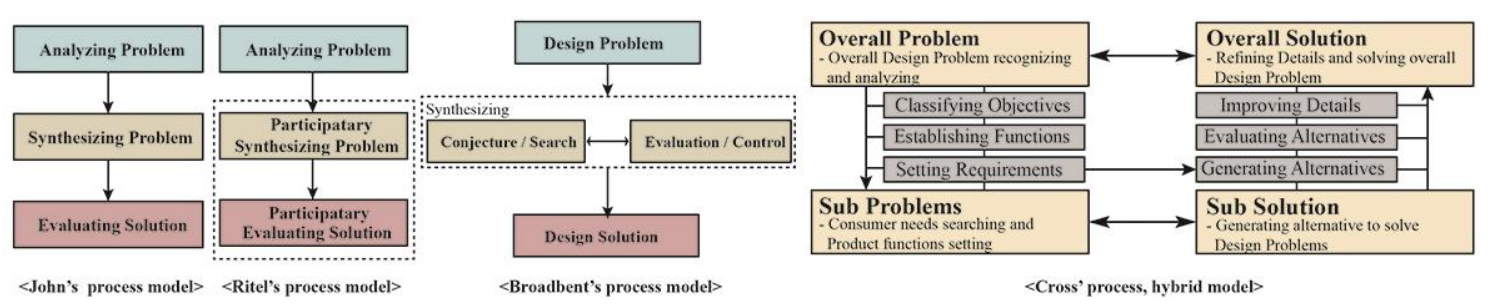

Fig. 1 First generation EDP, Johns; second generation, Ritel; third generation, Broadbent; and Cross' hybrid model

To live up to the demands of the times, Ritel's second-generation participant process complemented and improved the first-generation participant process and Broadbent's process specified the tasks in "synthesizing" step, improving the linear model to some extent. In the 1990s, Nigel's hybrid model refuted Broadbent's, as it was an asymmetric model designed to respond to a more complicated and diversified society, industrial environments, and consumers [16], [17], (Fig. 1).Cross' hybrid model (HM) is multi-layered and circular, rather than linear, in order to solve design problems and present solutions to complicated problems by utilizing a combination of existing EDP theories that broke out of the existing linear structure [12]. The HM multi-stratified design problems and classified them as overall problems (OP) and subproblems (SP). It further cross asserted that there is asymmetric balance and relation between OPs and overall solutions (OS) and between SPs and sub-solution (SS), and there is a hierarchic correlation between each problem and its solution rather than a one-way relation [12]. Starting with the above-stated assumption, the hybrid model was designed to "classify objectives" in order to begin with general problems and grasp them at the base; generating alternatives that start with establishing functions, setting requirements, and solving problems, and then inducing general solutions; and specific assignments of evaluating alternative and improved details [12], (Fig. 1). 
With awareness to the specific assignments stated above, the designer divided general problems into sub-problems, and added sub-solutions for the sub-problems in order to propose a general solution through the design work [18]. The HM specified the designer's role further by applying a diversified structure. In Figure 1, the problem-solving system engineering (general solution, subsolution) is on the right side with marketing as the general and sub-problems, and roles of Design is located inside of the rectangle structure of OP, SP, SS, and OS as a specific assignment and plays a role as a regulator [19], [20]. With this structure, Cross' hybrid model induces problemsolving by integrating complex perspectives in the design industry. The HM integrates complex concepts of engineering, marketing, and design as a mediator [19], and thus it may be viewed as a basic framework for convergence design processes. In the context of process implementation, however, aspects of engineering are emphasized, while design work is limited only to the external features of a product. Besides, product concepts and storytelling, which attract consumers in this era of variety, are neglected, and the buffering role of designers is emphasized in terms of symmetry, hierarchy, and correlation of problems and solutions. Accordingly, there is a concern that designers' creativity might be diluted [21]. As designers' concepts and creative production of results in the area of fashion design are currently viewed as important as the efficiency of process performance, a design process for convergence between fashion and technology needs to include a conceptual structure that can support designers' creativity. This is an issue in the context of Cross' HM. Therefore, this study seeks to examine the FDP that puts designers' creativity at the center of the process and thus makes up for the weak points of the HM.

\subsection{The FDPs considered for this study}

FDPs have been studied and developed along with EDPS in order to efficiently manage design, production, management, marketing, and promotion as well as product plans since the fashion industry began to expand in the late $20^{\text {th }}$ century [22], [23], [24]. Most FDP models are indirectly based on EDP models and intended for industrial designers or senior-level students [25]. [26], [27]. The basic form of the preliminary models was derived from Wallas' (1926) model consisting of four steps: preparation, incubation, illumination, and verification, and Koberg and Bagnall's (1974) model consisting of seven steps: acceptance, analysis, definition, ideation, selection, implementation, and evaluation. These two models were generally adapted and adjusted for apparel design in FDP studies (Watkins; Davis; Lamb \&Kallal; Regan et al.) for industrial apparel design [28]. Davis' (1980) and Lamb \&Kallal's (1992) models consisted of six courses in order to fit with the structures of previous FDP models (see Tables 1 and 2).

Table 1. Davis' fashion design process

\begin{tabular}{|c|c|}
\hline Set a goal & $\begin{array}{l}\text { Visual references or cases on literature, culture, costume history, target consumers, and } \\
\text { markets researches should be conducted. }\end{array}$ \\
\hline \multicolumn{2}{|r|}{$\downarrow$} \\
\hline $\begin{array}{l}\text { Examine outside } \\
\text { influence }\end{array}$ & $\begin{array}{l}\text { Identities of products should be extracted through the analysis of the information } \\
\text { gathered in the previous step. }\end{array}$ \\
\hline \multicolumn{2}{|r|}{$\downarrow$} \\
\hline Establish criteria & $\begin{array}{l}\text { The most suitable guidelines for product functionality, materials, and structures should } \\
\text { be configured through market research. }\end{array}$ \\
\hline \multicolumn{2}{|r|}{$\downarrow$} \\
\hline Make the plan & $\begin{array}{l}\text { The application methods for materials, colors, and designs should be planned according } \\
\text { to the guidelines. }\end{array}$ \\
\hline \multicolumn{2}{|r|}{$\downarrow$} \\
\hline Carryout the plan & The design plans extracted in the previous step should be realized. \\
\hline & $\downarrow$ \\
\hline
\end{tabular}


International Journal of Education (IJE) Vol.8, No.1, March 2020

Evaluate the product $\quad$ The realized product should be evaluated before releasing the final product.

Table 2. Lamb \&Kallal'sfashion design process

\begin{tabular}{|c|l|}
\hline Problem identification & Problems should be understood before investing in possible solutions. \\
\hline Preliminary ideas & $\begin{array}{l}\text { Case study, survey, brainstorming, and sketches should be conducted to extract design } \\
\text { samples. }\end{array}$ \\
\hline \multicolumn{2}{|c|}{$\downarrow$} \\
\hline Design refinement & Tasks for realizing and improving design variations should be conducted. \\
\hline Prototype development & Design selection and prototype development should be performed. \\
\hline \multicolumn{2}{|c}{$\downarrow$} \\
\hline \multicolumn{2}{|c|}{$\downarrow$} \\
\hline Evaluation & $\begin{array}{l}\text { Prototypes should be evaluated by the three criteria, namely functionality, } \\
\text { expressiveness, and aesthetic. }\end{array}$ \\
\hline Implementation & Designs should be modified by the evaluation results until the mass-production deadline. \\
\hline
\end{tabular}

Watkins' (1988) and Regan et al.'s (1998) models were designed with seven steps similar toKoberg\& Bagnall's case (see Tables 3 and 4).

Table 3. Watkins' fashion design process

\begin{tabular}{|c|c|}
\hline Acceptance & The motivation for the investigation of design problems and solutions should be understood. \\
\hline \multicolumn{2}{|r|}{$\downarrow$} \\
\hline Analysis & $\begin{array}{l}\text { Basic study of the market and consumers should be conducted. } \\
\text { Inspiration for methods should be investigated through problem definition and interviews. }\end{array}$ \\
\hline \multicolumn{2}{|r|}{$\downarrow$} \\
\hline Definition & The most appropriate idea should be selected for the problem solving. \\
\hline \multicolumn{2}{|r|}{$\downarrow$} \\
\hline Ideation & A concept based on the idea in the previous step should be generated. \\
\hline \multicolumn{2}{|r|}{$\downarrow$} \\
\hline Idea selection & $\begin{array}{l}\text { A specific design concept should be configured by synthesizing results of the previous } \\
\text { ideation. }\end{array}$ \\
\hline \multicolumn{2}{|r|}{$\downarrow$} \\
\hline Implementation & $\begin{array}{l}\text { Design variations should be extracted based on the design concept as a criterion. } \\
\text { Prototypes should be made to realize the designs. }\end{array}$ \\
\hline \multicolumn{2}{|r|}{$\downarrow$} \\
\hline Evaluation & $\begin{array}{l}\text { The prototypes should be evaluated using the criteria. } \\
\text { Improvement points should be generated to improve the quality of the product. } \\
\text { The final product should be established before releasing it to markets. }\end{array}$ \\
\hline
\end{tabular}

Table 4. Regan et al.'s fashion design process

\begin{tabular}{|c|l|}
\hline Problem recognition & Defining problems, generating basic ideas, and arranging ideas should be conducted. \\
\hline \multicolumn{2}{|c|}{$\downarrow$} \\
\hline Problem definition & $\begin{array}{l}\text { Directions for the product design, information on material resources, and product ranges } \\
\text { should be researched. }\end{array}$ \\
\hline \multicolumn{2}{|c|}{$\downarrow$} \\
\hline $\begin{array}{c}\text { Exploration of } \\
\text { problem }\end{array}$ & $\begin{array}{l}\text { Consumer information, product demands, re-order strategy, and market circumstances } \\
\text { should be investigated. }\end{array}$ \\
\hline
\end{tabular}


International Journal of Education (IJE) Vol.8, No.1, March 2020

\begin{tabular}{|c|c|}
\hline Search of alternative & $\begin{array}{l}\text { Product lines should be edited and suggested to synthesize the experiences according to } \\
\text { the needs and conditions of designs from the previous season. }\end{array}$ \\
\hline \multicolumn{2}{|r|}{$\downarrow$} \\
\hline $\begin{array}{l}\text { Evaluation \& } \\
\text { decisions }\end{array}$ & $\begin{array}{l}\text { The results of the previous step should be assessed using the criteria that consist of the } \\
\text { perspectives on aesthetics and salability. }\end{array}$ \\
\hline \multicolumn{2}{|r|}{$\downarrow$} \\
\hline $\begin{array}{l}\text { Specification of } \\
\text { solution }\end{array}$ & $\begin{array}{l}\text { The result of the evaluation should be synthesized and analyzed to suggest the best } \\
\text { product lines and quantities for production management. }\end{array}$ \\
\hline \multicolumn{2}{|r|}{$\downarrow$} \\
\hline $\begin{array}{l}\text { Communication of } \\
\text { solution }\end{array}$ & $\begin{array}{l}\text { Linguistic and visual guidance for the products, manufacture, and distribution should be } \\
\text { confirmed and conveyed to the management and sales departments.. }\end{array}$ \\
\hline
\end{tabular}

FDPs from the 1980s to 1990s could be defined as methodologies which were developed for use in the industrial mass production of existing brands or companies. On the other hand, in FDP for creative practice in education, industrial efficiency and logic are not only significant, but play a leading role in stimulating a more sophisticated ideation in students, as well as for making iterative efforts to achieve design goals and establish design identities [13], [29]. In this regard, the design cycle (DC) as a FDP could be used to meet academic needs to promote creativity, continuous thinking, and practicing. Diffenbacherpresented the DC diagram to underline the importance of the philosophy beyond the visual elements. To achieve the above conceptual tasks, the DC helps designers' iterative self-evaluation and process-tasking with its circular structure [13], (see Figure 2).

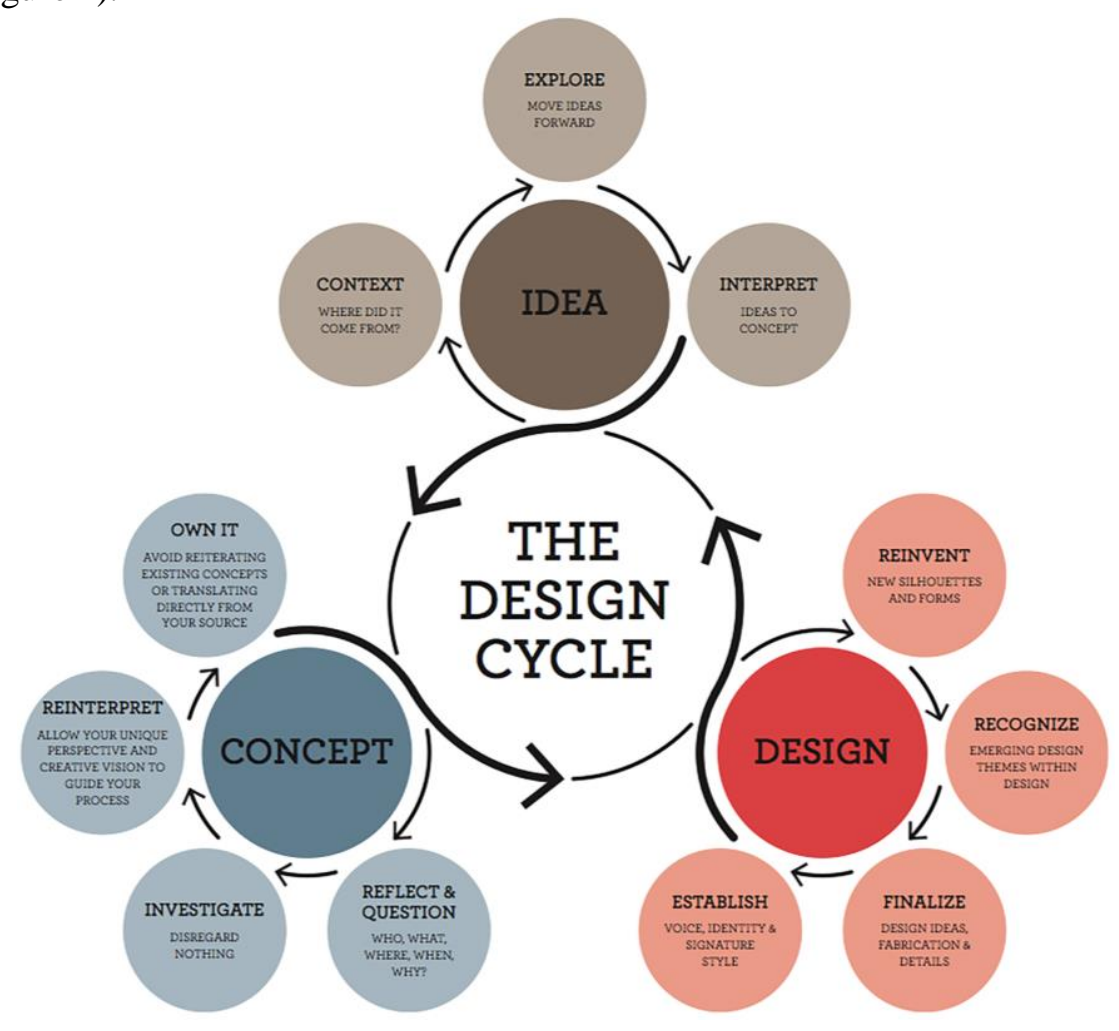

Fig. 2 The Design Cycle [31]

First, in the IDEA part of the process, the "context" stage suggests finding inspiration from diverse sources. The "explore" stage suggests moving students' thinking forward by seeking clues for ideas from their direct experiences and memories, through taking photos, interviews, or surveys rather than indirect sources such as magazines, the internet, or video clips. The "interpret" stage is the synthesis of the results of the previous steps [13]. 
Second, in the CONCEPT part of the process, The "reflect \& question" stage suggests clarifying design problems and making this the basis for the definition of ideas by using indexes of "what," "who," "where," "when," "why," and "how." The "investigate" stage suggests solving the problems specified in the previous step through deeper investigation using literature or visual materials to go beyond existing concepts. The "reinterpret" stage suggests translating the results of the previous investigation from students' distinctive perspectives. With this step, students should physically undertake a variety of tasks such as collage making, drawing, collection, writing, and arranging resources on their research notes to be distinct from existing concepts [13].

Third, in the DESIGN part of the process, the "reinvent" stage suggests creating design variations with new silhouettes and forms. The "recognize" stage suggests refining and elaborating designs by considering new design elements generated from the design task. The "finalize" stage suggests fixing materials, colors, and details according to the reinvented design theme, and the "establish" stage suggests presenting the distinctive identity of the designer as well as the signature style of the collection [13].

Since this study aimed to investigate the methodology for assisting convergence design practice by combining fashion's aesthetic perspectives and electronics' digital functions from the viewpoint of students' distinctive identities or perspectives, it was decided to incorporate the design cycle as this study's design method, rather than the FDPs based on EDP.

\subsection{The interaction design process in this study}

In general, interaction design deals with interactions among humans, between humans and things, and among things. The boundaries of interaction design have been expanded and subdivided by the growth of IT. Interaction design is generally recognized as the design area that deals with human interaction with a diversity of products, services, systems, and social components [30], [31], [32]. In regard to users' needs and the properties of the design results, interaction design pursues harmonization between diverse academic, social, and industrial areas such as psychology, computer science, electronics, and so on, among others. Interaction design incorporates two directions: substantial interaction of things, such as the physical interaction between human and electronic products and intangible interactions, such as services in virtual spaces or the system algorithm of websites [31], [32], [33]. Interaction design consists of four conceptual approaches: user centered design, action centered design, system centered design, and genius design [30], (Table 5).

Table 5. Conceptual approaches of interaction design by purpose

\begin{tabular}{|c|l|}
\hline Approach & \multicolumn{1}{c|}{ Outlines } \\
\hline $\begin{array}{c}\text { User centered } \\
\text { design }\end{array}$ & $\begin{array}{l}\text { Every design problem and requirement, such as function, structure, and value is up to } \\
\text { consumers. }\end{array}$ \\
\hline $\begin{array}{c}\text { Action centered } \\
\text { design }\end{array}$ & $\begin{array}{l}\text { "Action" including consumers' behavior and decision making is the goal for use of the } \\
\text { product or service rather than consumer' aesthetic tastes. }\end{array}$ \\
\hline $\begin{array}{c}\text { System centered } \\
\text { design }\end{array}$ & $\begin{array}{l}\text { Seriality of the processed phenomenon occasioned by users' activities or the context and } \\
\text { structure of systems that generate the processed phenomenon. }\end{array}$ \\
\hline Genius design & $\begin{array}{l}\text { Designers' individual talents and skills is the most popular approach in both academia and } \\
\text { industry, and many companies such as Apple use this approach to secure their brand identity } \\
\text { as well as technologies. }\end{array}$ \\
\hline
\end{tabular}

The four approaches of the interaction design process generally consist of four stages [30], [33]. In the first "Identifying alternative needs and establishing requirements" step, investigation and 
analysis tasks are performed to establish the design strategy. The investigation task is performed to understand design problems and users' needs. The analysis task is conducted to extract a structured insight. Based on the results of the two tasks, designers create new alternatives (designs) that differ from existing designs and clarify requirements for primary consideration in every stage of the process. In this step, the requirement, is generally organized as a self-question and answer. In the question and answer, designers specify the target users, purpose of functions, users' activities, and operability of designs.

In the second "(Re)Design" step, alternatives that can satisfy the requirement are created. The designing tasks should be not only focused on visual aspects, but also fully consider the using scenario and context of system operation. In this stage, if drawbacks of the alternatives according to the requirement are detected, designers should return to the previous stage and re-perform the investigation of market, users' needs, and the analysis of the requirement.

In the third "Building interactive version" step, developed prototypes that are interactive are evaluated for operability. If there are negative finding, such as errors in the interaction between users and prototypes, designers should go back to the previous stage to supplement the issues.

In the fourth "Evaluate" step, prototypes are evaluated to judge whether design problems have been solved or not. If the problems are cleared and the requirement has been met successfully, the prototypes are used as the final product. However, if there are drawbacks in the usability of the prototypes, designers should go back to the second stage to re-investigate appropriate structure and actuation principle for alternatives. Moreover, if there are critical errors in the context of system operation, designers should go back to the initial stage of the process to completely understand the requirement.

Through thetasks, the interaction design process encourages designers to maintain flexible thinking and attitudes for returning to the previous tasks to refine their works repeatedly, when they judge that the result of the process has been inadequate for achieving the ultimate goals.

\section{Investigation of the Method of Practice for Convergence FASHION PROTOTYPE DEVELOPMENT}

\subsection{Initial study of the convergence practice}

\section{Framework of the primary practice model}

The study aimed to incorporate the conceptual elements related to specific steps and tasks required to realize substantial convergence. Participants interested in the tasks were recruited for the workshop. The workshop was held over 10 weeks, one class per week lasting three hours, as the workshop was intended to evaluate whether the process could be adapted as a short program for convergence design practice.

In the first stage, "clarifying the objective," the concepts "context" and "explore" in the IDEA part of the DC were applied to lead the participants (designers and engineers) to seek "overall problems" together as creative-logical thinkers. In the second stage, "establishing functions," the concepts "interpret" and "reflect \& question" in the IDEA and CONCEPT parts were applied to encourage engineers to actively participate in discussions about designers' ideas on wearable technologies.In the third stage, "setting requirements," the concepts "investigate," "reinterpret," and "own-it" in the CONCEPT part were applied so that students extracted concrete design concepts for the "sub-problem." In the fourth stage, "generating alternatives," the concepts "reinvent" and "recognize" in the DESIGN part were applied to induce designers to create design 
variations and improve them through self-evaluation for the "sub-solution."In the fifth stage, "evaluation alternatives," the concept "finalize" in the DESIGN part was applied to lead the students to understand and supplement any insufficiencies in the prototypes. Finally, in the sixthstage, "improving details," the concept "establish" in the DESIGN part was applied in order to present the established prototype as an "overall solution."

\section{Participants}

In order to verify the usability of the primary practice model, the convergence fashion design and development workshop was conducted with 3 designers and 3 engineers, with an age range from 23 to 25 years of age. They were interested in how convergence works but had no experience of it. The participants were divided into three teams, and each team was composed of one designer and one engineer. In order to investigate the wider usability of the practice model for low-level students, the recruitment of participants was limited to junior level and not senior level, but experience of classes such as Construction on the fashion course and Circuit Design and Processing on the electronics engineering course were required of the participants in order to test the usability of the workshop as an R\&D practice model. All of the students (participants) were requested to actively discuss and share their specialties with each other.

\section{Workshop procedure}

The primary workshops were held over a 10-week period from March 10, 2016, to May 12, 2016. Early in the workshops, the conception, as stated by the instructor's guidelines, was intended to embody the general context of the idea to develop convergence fashion prototypes.

The first step was an introduction to the goals of convergence practice and process tasking, and discussions of the practice processing were conducted to decide on the basic context for CFPD. Two basic directions were configured: light for aesthetic expression through a combination of a garment and system utilizing light source technology, and complexity for constructing a complex expression through lights and shape changes.

For the second step, with the instructor's help, each development team specified ideas through sketches: operation scenarios of the applied technologies and system requirements were drawn according to the six principles (what, who, where, when, why, and how), and the four basic components of digital systems: input, output, control, and power.

For the third step, designers were encouraged to collect diverse references to configure design concepts and analyze them from their own perspectives. Further, each team synthesized the results of the previous processes to clarify the specific outlines of the development concepts of their prototypes for aesthetic fashion and technological expression.

For the fourth step, drawing on the digital expression provided by the sample circuits, each designer was asked to balance the expressions of fashion and digital technology, and it was discovered that lighting expression was much stronger than the garments' visual elements. After some refinement, designers modified the flat patterns according to the instructor's advice so that the device would not cause any adverse effect to the human body. The engineers reorganized the systems according to the actual size of the garments and wrote codes to temporarily embed systems in the garment platforms.

For the fifth step, the aesthetic characteristics of the prototypes and the operability of the systems were evaluated. The students and instructors evaluated these together as to whether or not the intended expression through the embedded systems was integrated successfully with the concept. With the wearability of the garment and the operability of the system as the criteria, each 
prototype was assessed and tested. Thereafter, any small drawbacks that needed to be improved were discovered.

For the sixth step, each $R \& D$ team completed the prototype after reflection on improvements suggested in the previous step. After the refining tasks were completed, the established prototypes were presented at the last section of the workshop.

\section{Design results of the workshop}

As the result of the primary study on CFPD practice, three prototypes were designed, refined, developed, and established. In the third step, overall design variations were created, and in the fourth and fifth steps, the designs were elaborated for a balance between the visual expression of fashion and electronic technology (Table 6).

Table 6. Overview of the design development and technological application for each prototype

\begin{tabular}{|c|c|c|c|}
\hline Prototype designs & \multicolumn{2}{|r|}{ System Devices } & Ideas for the Development of Prototypes \\
\hline & Input & Bluetooth Text System & \multirow{4}{*}{$\begin{array}{l}\text { The motif of this system is a street artist using } \\
\text { graffiti for self-assertion. } \\
\text { The wearer can display a message by reflecting } \\
\text { light on the surface of the hip-hop style garment } \\
\text { like a screen. }\end{array}$} \\
\hline & Output & High-brightness LED panel & \\
\hline & Control & Arduino Mega & \\
\hline Stree & Power & $12 \mathrm{~V}$ & \\
\hline \multirow{4}{*}{ One-piece dress } & Input & Illumination sensor & \multirow{4}{*}{$\begin{array}{l}\text { The main concept is Taiwanese cultural } \\
\text { characteristics. The skirt pattern changes into the } \\
\text { image of a Chinese traditional hanging lantern } \\
\text { The lighting inside the decorative object of } \\
\text { traditional handicraft style is turned on and } \\
\text { represents light and shape changes, emphasizing } \\
\text { "spatial senses." }\end{array}$} \\
\hline & Output & $\begin{array}{c}\text { Red } 3 \pi \text { LED, step motor } \\
\text { \&wire tube }\end{array}$ & \\
\hline & Control & Arduino Nano & \\
\hline & Power & $5 \mathrm{~V}$ & \\
\hline \multirow{4}{*}{ Floral robe } & Input & Illumination sensor & \multirow{4}{*}{$\begin{array}{l}\text { The artwork of a flower image on the robe's } \\
\text { surface responds to the brightness of the } \\
\text { surroundings: If the surroundings are bright, it } \\
\text { blossoms with the light source inside the pistil and } \\
\text { flower structure turned on. The light and shape } \\
\text { change, emphasizing the decoration of a flowery } \\
\text { image. }\end{array}$} \\
\hline & Output & $\begin{array}{l}\text { White } 3 \pi \text { LED \&micro } \\
\text { motor }\end{array}$ & \\
\hline & Control & Arduino Nano & \\
\hline & Power & $5 \mathrm{~V}$ & \\
\hline
\end{tabular}

In the case of R\&D team A, designer A developed the street-styled two-piece outfit; the lose fitted T-shirt and wide pants were patterned with images inspired by graffiti art in balance with the expression of fashion and technology. Engineer A developed and refined bluetooth texting to create a communication system for message-lighting expression. In the final step, the designer and engineer combined their platforms and systems to create the "street-wear" garment. In the case of R\&D team B, designer B developed the Chinese-style dress with a Taipei textile pattern inspired by a photo-montage technique. Engineer B developed LED lighting and shape changing systems composed of red LEDs, step motors, and wire-tubes attached to the inner-surface of the dress to transform the shape of the skirt, thereby making it seem like Chinese lanterns were attached to it. In the last step, they combined the fashion platform and the electronic system to create the "one-piece dress." In the case of $\mathrm{R} \& \mathrm{D}$ team $\mathrm{C}$, designer $\mathrm{C}$ developed the robe-style dress with a flower pattern. Engineer $\mathrm{C}$ developed LED lighting and shape changing systems composed of white LEDs, micro motors, and transparent wires embedded in the flowers on the outside of the dress, which could open and close the petals of the flowers as they reacted to the 
brightness of the environment. In the final step, they assembled the platform and the complex system to create the "floral robe" (Fig. 3).

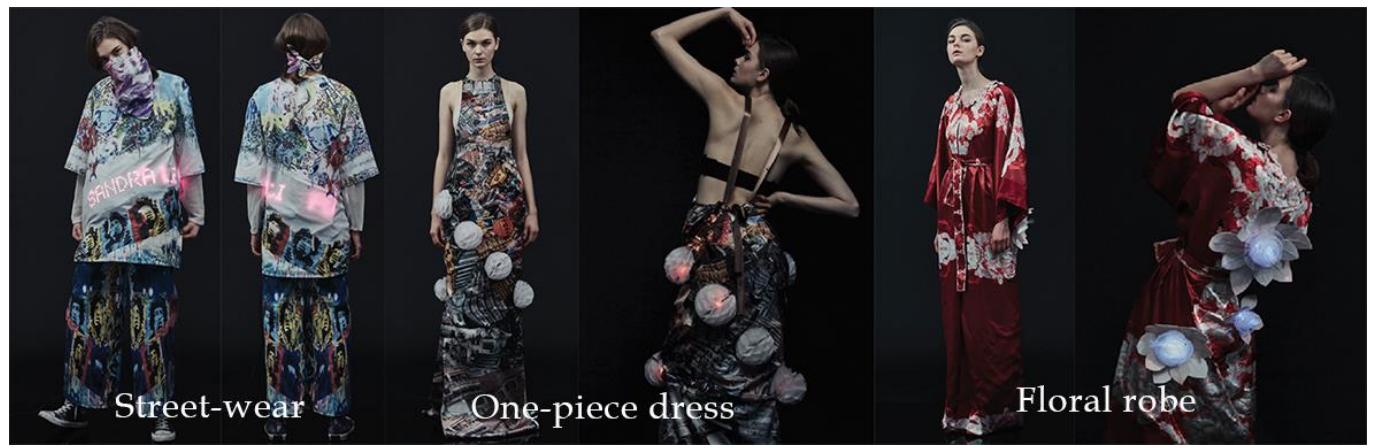

Fig. 3 The three prototypes: street wear, one-piece dress, and floral robe in the primary study

\section{Learning outcomes of the workshop}

From the primary study of CFPD practice, designers were encouraged to improve the prototypes' aesthetics and structural problems continuously throughout the process, and they followed the guidelines to make the iterative efforts independently when, for example, they discovered problems in the visual stimuli. Thus, the unbalanced roles of designers and engineers generally found in convergence R\&D projects was rebalanced to some degree. However, such continued conception and modification for improvement could be achieved within the boundaries of each professional area: design and engineering. Designers concentrated on enhancing the visual expressions of the garment platforms with their artistic skills, and engineers concentrated on achieving working systems in the prototypes. Therefore, based on the experience of the primary study, it was confirmed that there was a necessity for refining the design process and practice model of CFPD, which could underline the in-depth cooperation so that the students actively share their expertise, knowledge, and skills with each other, such as use of technology from the design perspective or systematic garment design from the engineering perspective.

\subsection{Refined study of the methodology of CFPD practice}

\section{Refined framework for the CFPD model reflecting the concepts of IDP and TDC}

Based on the results of the primary study, this study's practice model was re-designed to promote both types of students sharing expertise willingly and making their processes more interactive. The study sought to improve the convergence fashion design process (practice model) focusing on the concept of the interaction between users and convergence products.

Convergence fashion products would be completed by the fusion of fashion platforms structures and electronic systems for functions. Accordingly, principles and properties of human-computer or human-machine interfaces could be reflected in the final product. In addition, as the platform that embraced the interactive system was the medium of garments, the products should be aesthetically attractive to users. Although the convergence fashion prototypes of the primary study were developed to achieve balanced visual expressions between fashion and electronic engineering, they were the inventors' focused functions, and their input mechanisms were up to the environmental stimuli rather than the interaction with their wearers. Therefore, to encourage the ideation, research, and development of wearer (user) focused convergence fashion, it was considered that the concept of interaction design process (IDP) would be helpful for CFDP on two points: interactivity of garment systems and aesthetic fashion concepts. Asthe DC consists of a circular process for the improvement of design results, there were structural and conceptual 
similarities with IDP. Iterative process fulfillment is also emphasized in IDP to deal with user-and function-oriented design thinking. The user-focused or function-oriented design thinking combined method may promote a revised view of design research and the motivation for the indepth cooperation of students who are not familiar with complex design thinking or working with each other. For the purpose of the study, IDP as the overall base-mission and the DC as a specific sub-mission were combined as regards their structural similarity as well as this study's goal.

At the first stage, "identity needs \& establish requirement," the concepts "context" and "explore," "interpret," and "reflect \& question" steps in the IDEA and CONCEPT parts of the DC were applied for combining the two directions: understanding design problems from the interactive and analytical perspective of IDP and the aesthetic perspective of the DC. At this stage, the instructor required in-depth investigation of the background of the design problems and users' needs to extract the requirements for the interactive design concept and create guidance for the garments' design and technology concepts. In addition, students had to obtain text, diagrams, and photos to demonstrate their own ideas created by their primary studies.

At the second stage, "(re)design," the concepts "investigate," "reinterpret," and "own-it" in the CONCEPT part were applied to suggest guidelines for the specific ideation of "aesthetics," "originality," and "interactive functionality." In this stage, the instructor required all students to organize their ideas and create design sketches or scripts indicating the structures of garment platforms and actuating scenarios or situations with electronic systems.

At the third stage, "build an interactive version," the concepts "reinvent," "recognize," and "finalize" in the DESIGN part were applied to guide the optimum integration of garment platforms and electronic systems, with the integration achieved through iteration. The instructor required students to arrange their results according to the fashion factors: colors, materials, forms, and wearability, as well as the engineering factors: operability and stability. In addition,designers and engineers had to share their processes of making and experimenting to discover better means for each task before they combined the platforms and systems.

At the fourth stage, "evaluate," the usability and wearability of the interactive prototypes were evaluated to judge whether the requirement had been met. If the requirement was met, the prototype would be established as the final product. However, if there were any problems with the completeness of the prototypes, students had to go back to the previous stage to solve the problem. Since, this study aimed to integrate fashion platforms and electronic functions, it was considered that any problems in each area had to be solved together. Thus, in this study, the evaluation and refinement processes in IDP were integrated.

\section{Participants}

To investigate the usability of the practice model of CFD consisting of IDP and TDC, four designers and four engineers participated in the convergence fashion product R\&D workshop. All participants were newly recruited to verify objectively whether the practice model could be followed up by inexperienced students who no knowledge of convergence design practices. The age range of the participants (sophomore and junior level) in each department was 22 to 25 years old. Each R\&D team was divided into four teams, a designer with an engineer at the same academic level in each, since this study had been planned to verify the usability of the model for a wide range of students' year levels. Just as with the participants in the primary study, there was the condition that participants had previously taken a making classes, for example, Construction on the fashion course and Circuit Design and Processing on the electronic engineering course, since this study aimed to research the substantive method of product development practicing in fashion design education. 


\section{Workshop procedure}

The workshops were held over 15 weeks from May 8, 2017, to August 14, 2017. There were more workshops than in the primary study, as the applicability of the second process had to be verified more systematically in order to adapt the design practice program in fashion design education.

In the first step, "context," and "explore," each student conducted ideation and discussion of design problems related to targeted users and functional concepts for the users focused on the interaction among the users, garments, and systems.

In the second and third steps, interpret" and "reflect \& question," each R\&D team organized the result of the research in step one, and then they organized their ideas according to the six principles ofthe DC (Table 7).

Table 7. Example of the organized outlines of prototype development ideas according to the six principles

\begin{tabular}{|l|l|l|l|l|l|}
\hline What & Where & When & Who & Why & How \\
\hline $\begin{array}{l}\text { Touchable- } \\
\text { wear }\end{array}$ & $\begin{array}{l}\text { Outdoor } \\
\text { space } \\
\text { such as } \\
\text { streets }\end{array}$ & $\begin{array}{l}\text { When its } \\
\text { users are } \\
\text { walking or } \\
\text { moving. }\end{array}$ & $\begin{array}{l}\text { Hearing- } \\
\text { impaired } \\
\text { people. }\end{array}$ & $\begin{array}{l}\text { To encourage active } \\
\text { and safe outdoor } \\
\text { activities. }\end{array}$ & $\begin{array}{l}\text { Through sound sensor and } \\
\text { vibration motor systems, the } \\
\text { garment detects potential danger } \\
\text { approaching from the rear. }\end{array}$ \\
\hline
\end{tabular}

In the fourth step, "investigate," the prototype development concepts were selected via a survey investigation in which 56 student respondents from diverse majors and age groups assessed the usefulness of the proposed ideas. Once the respondents understood the outline of each idea, they were asked to select only one idea as the most appropriate for themselves or other people. Consequently, fourideas were extracted for prototype development (Table 8).

Table 8. Results of the respondents preference survey (selected ideas in the shaded blocks)

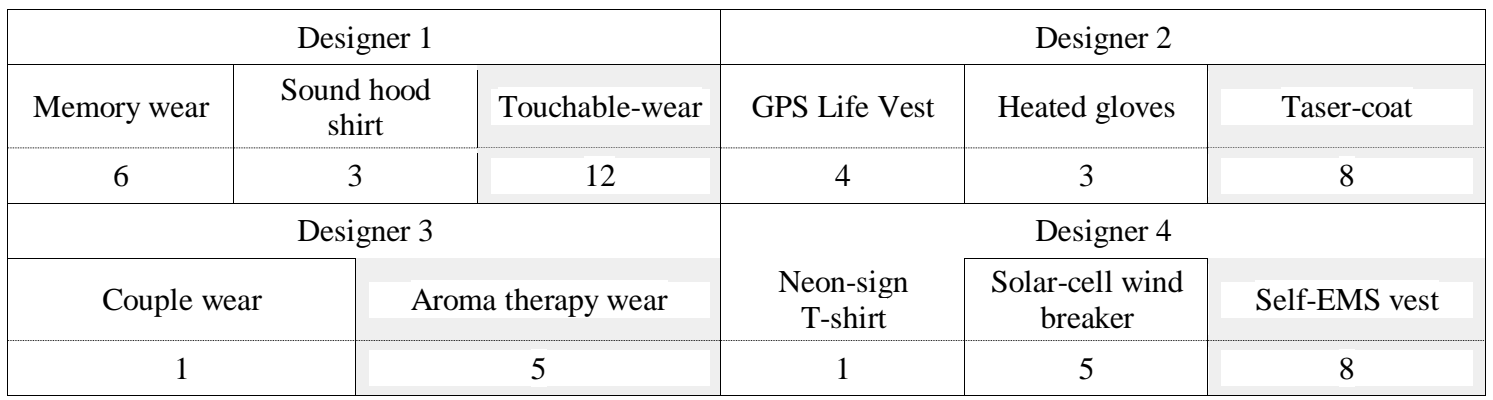

In the fifth step, "reinterpret," each team had configured devices according to the four criteria: input, output, control, and power (Table 9). They then made data sheets for the devices' specifications of performance, size, and weight.

Table 9. Outline of system devices in each prototype development idea

\begin{tabular}{|c|c|c|c|c|}
\hline & Touchable Wear & Taser-coat & Aroma Therapy Wear & Self-EMS Vest \\
\hline Control & Arduino nano & Arduino nano & Arduino nano & Arduino nano \\
\hline Input & $\begin{array}{c}\text { Sound Sensor, AUX } \\
\text { Cable }\end{array}$ & $\begin{array}{c}\text { Ultrasonic sensor, } \\
\text { camera, switch }\end{array}$ & Heartbeat sensor & Toggle switch \\
\hline Output & $\begin{array}{c}\text { Vibration motor, } \\
\text { woofer speaker }\end{array}$ & $\begin{array}{c}\text { LCD Display, LED, } \\
\text { conductive PLA panel }\end{array}$ & Air pump & Air pump \\
\hline Power & 5V battery & 12V battery & 5V battery & 5V battery \\
\hline
\end{tabular}


In the sixth step, "own-it," each designer was encouraged to create design variations of the garment platforms based on their R\&D concepts and the equipment methods of system devices. Engineers searched usable electronic parts drawing on the designers' work. After the designs were fixed through tutorials, each team designed the diagram of the entire system of circuits and investigated installation methods and used Velcro tape for fixing the system devices into the garment platforms.

In the seventh step, "reinvent," each team researched the locations of the system installation and then drew diagrams to organize the results. Each designer drew flat patterns for muslin basting. They were required to mark the locations of the systems on the bastings to measure the real size and length between system devices and wires in order to adjust flat patterns regarding the measured data for the aesthetic completeness of the garment platforms as fashion items.Engineers initially simulated the operability of the systems to understand the adaptability of the spec for the devices they had selected for the interactive functions. Any problems with size, weight, actuation of the output devices of touchable wear, aroma therapy wear, and self-EMS vests were investigated. Consequently, each team was requested to re-think and design the actuation principle and adapt lighter, more accessible parts to ensure reliability. Then the engineers developed the refined system circuits based on the measured data from the muslin basting, and made all devices and circuit wires detachable by equipping socket-joints. 3D-printing technology was used to make covers for the hardware developed by the designers, and these were placed over each system device to enhance durability and to protect users' skin.

In the cases of the aroma therapy wear and self-EMS vest, the structures of their output device modules containing servo motors with rotating angles that could be controlled precisely by users' and were 3D printed to achieve the actuation principle (Fig. 4). At the end of this step, prefinalized garment platforms and the system circuits were temporarily assembled to evaluate completeness.
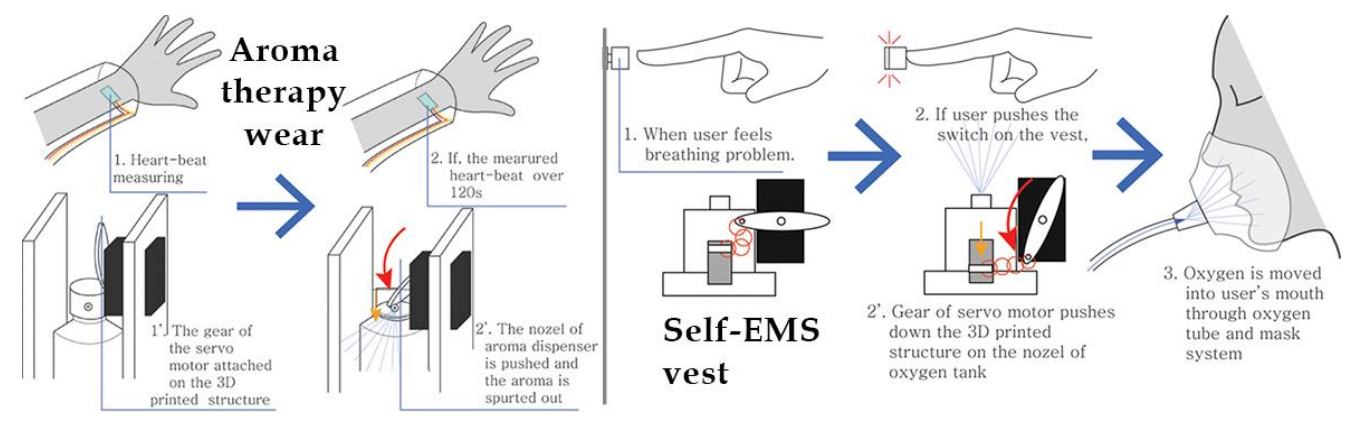

Fig. 4 Diagrams of the designers' operating principles integrated with the engineers' input

First, in touchable wear, there were two problems related to the range of the sensitivity of the sensor and its embedded location. The range of sensitivity had to be reduced down to the decibel level of car and truck horns, since the system had reacted to such low decibel sounds as people talking next to the wearer. There was also a miss-operation due to the location of the sensor. As the sensor was placed on the inner side of the rear hemline, it sometimes reacted to sounds caused by rubbing of the fabric. Second, for the taser-coat, there was an error in the usability of the system. When the quantity of the conductive PLA panels exceeded 4 pieces, the electric shock function did not operate properly. Third, in the aroma therapy wear, it was discovered that due to the form and volume of the 3D printed output device module, it was not suitable for embedding in the upper bodice. The installation of the input device was also inappropriate for constant monitoring of the vital signs, as the sensor was attached to the inside of the wrist part of the sleeve. Fourth, for the self-EMS vest, it was found that the location of the on/off switch and the structure of the output device module needed to be refined. As the on/off switchfor self-EMS 
function was embedded in the inside of the outer pocket containing the oxygen mask, it could not easily be pushed to activate the function and there was a concern about the miss-operation because of the embedded location. If the user made a strong movement, this could cause the mask to move and push on the switch. In addition, the structure of the nozzle pressing part of the 3D printed output module had to be extended to effectively push the nozzle on the oxygen tanks

In the ninth step, "finalize\& establish," the tasks of refinement of each prototype were conducted to solve any of the discovered drawbacks in the previous step (Fig. 5). The prototypes were retested and established as the final products in this R\&D practice.

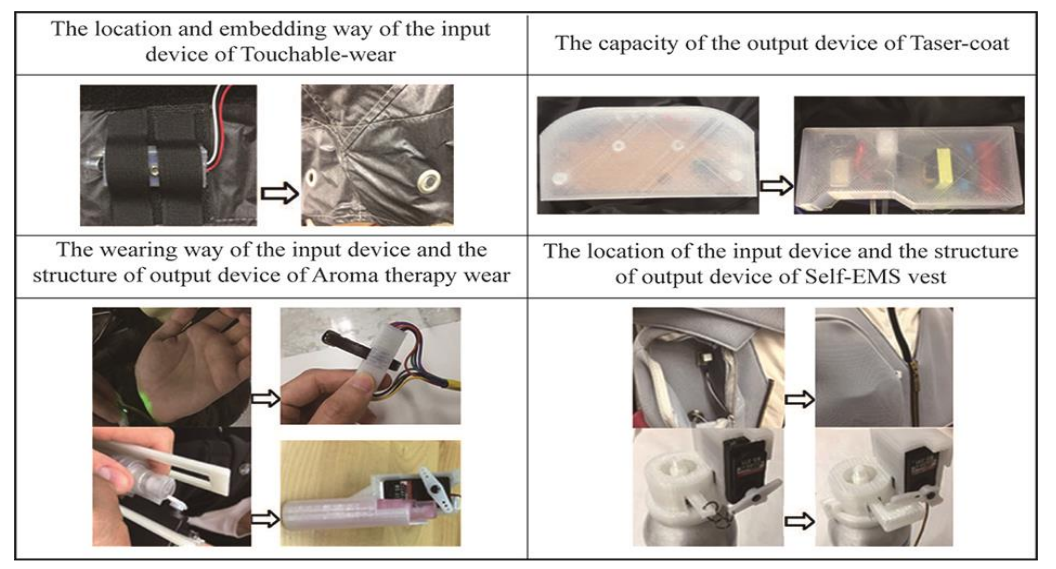

Fig. 5 The refinement of the system operability for each prototype

\section{Design of convergence fashion prototypes}

In the initial process of the R\&D workshop, the participants established the fundamental direction for the convergence fashion practice that aimed to develop prototypes providing user-focused functions for specific needs. The outlines of the designs and systems of the established prototypes are in Figure 6).

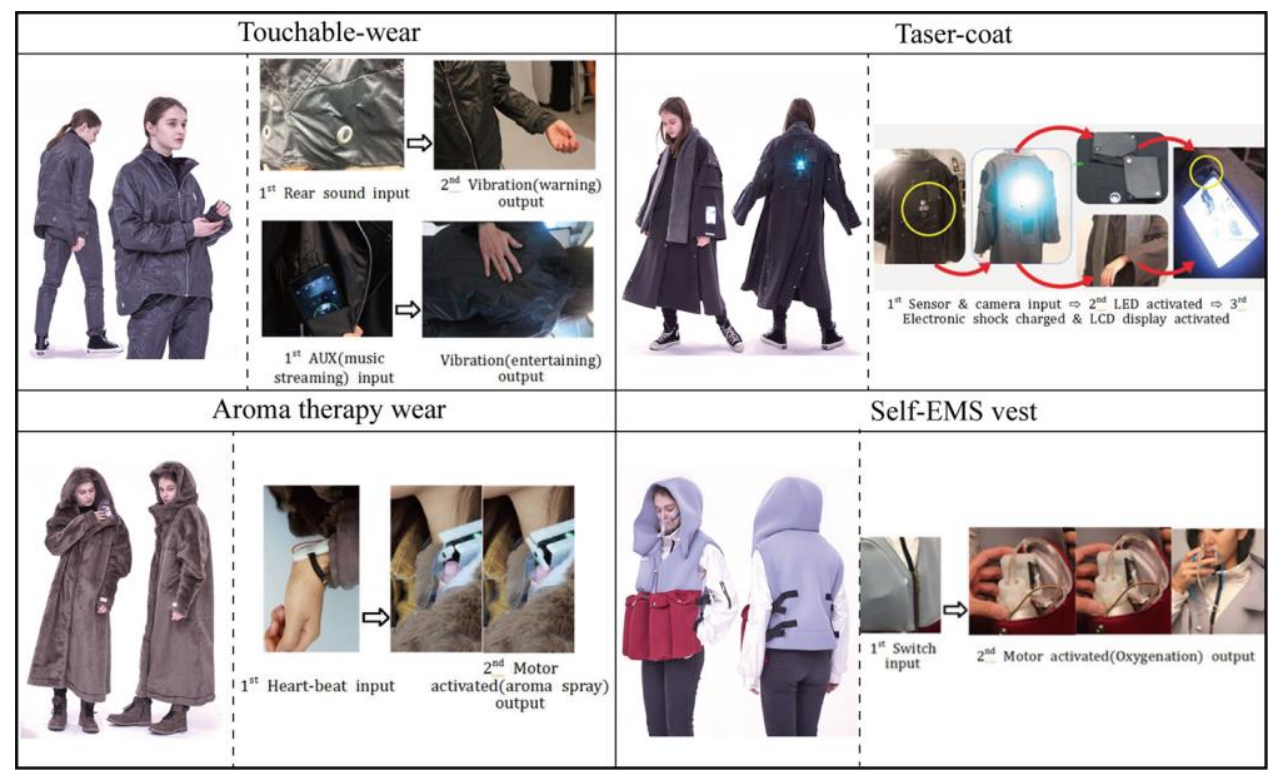

Fig. 6 The established convergence fashion prototypes and their operation principles 
First, touchable-wear was designed as sportswear, since the garment would be worn for outside activities such as walking on the street or jogging on a track. The prototype was planned to provide strong vibrations as warning signals when detecting sounds to help hearing-impaired people stay safe on streets. For example, when the user walked on the street, a sound sensor worked continuously at the user's rear side. If particular sounds at the decibel level of vehicle horns were detected, the system vibrated by means of vibration motors to let its user know the source of the sound. In addition, when the system was connected to a smart phone with an AUX cable, its user could 'feel'the beat of the music through weaker vibrations generated by woofers. The main system was embedded in the left-lower-side of the chest to ensure maneuverability, the four micro-vibration motors for feeling music were located on the middle part of the back, and the two coin-type vibration motors were embedded in the left and right wrist parts for the warning function.

Second, the taser-coat was designed as an oversized coat to cover its user's whole body and contain various input and output devices: ultrasonic sensor, micro-camera, LCD display, and conductive PLA panels. The prototype was planned to provide a safety ensuring function for women who leave work late at night. Through the super-sonic sensor, micro camera, highbrightness LED, and LCD display system, its user could observe what or who was behind her. Moreover, if somebody suspicious tried to touch her body, a highly amplified electronic shock would be generated by the PLA panels on the garment. The main system devices consisted of a processor, a LED, and a hyper-sonic sensor and were located on the upper back, and the display module was located on the lower left arm. Six conductive PLA panels were attached to both sides of the shoulders, arms, back, and waist. Due to the complex system devices connections, the circuit wires were located in the side seam lines and center back line, where the range of movement is relatively smaller than other parts of the body such as the waist.

Third, the aroma therapy wear was designed as an oversized coat with a high neck collar and hood to maintain the aroma as long as possible. In addition, the light brown color was used to induce a warm feeling in the user for psychological stability. The prototype was planned to provide an emotion-stabilizing function for people suffering from depression or panic disorder. Through heartbeat sensing and air pumping technologies, the garment recognized user's vital signs and released the aroma to decrease the user's stress level, when the system detected irregular signals from the heartbeat sensing data. The control, power, and 3D-printed output device module were located on the upper part of the left chest. The input device was an independent module like a watch worn on the wrist to gather heartbeat data and connected to the main control system by a minimal length of electronic wires.

Fourth,the self-EMS vest was designed to be for outdoor wear and incorporated large outer pockets to hold as many oxygen tanks as possible to extend the duration time of the function. The prototype was planned to provide an emergency medical care function for treating asthma attacks or respiratory diseases caused by particulates in the air, which is one of the biggest emerging issues in Korean society. Through air compression and pumping technologies, oxygen is supplied to users to relieve their symptoms. Since the output devices: oxygen mask and 3D-printed oxygen supply module, servo motor, and oxygen tanks were concentrically located on the right side of the bodice, the control and power devices were located on the opposite side of the body to balance the weight and the stability of the systems.

\section{Discussion of the refined practice}

The observed tendency of this study's CFPD practice of the participants consisting of this study's CFPD observed practices of designers and engineers are stated below: 
First, team D, touchable wear: designer A first ideated the rear sound detecting function, engineer A ideated the operation system and secondly suggested the additional function of sound through the vibration in the body. At the evaluation step, the designer and engineer detected the drawbacks of the system operation together. The designer suggested a possible solution for equipping the sensor, and the engineer provided a solution for the use of the alternative output device for the vibration function.

Second, team E, taser-coat: designer E ideated the crime prevention function, and engineer $\mathrm{E}$ designed the complex inter-connected input system and output system. At the experiment and evaluation processes stages, the engineer understood there was an electrical power issue for the number of electric-shock panels as pointed out by the instructor, and the engineer fixed the issue by developing a new power compressing circuit.

Third,team F, aroma therapy wear: designer $\mathrm{E}$ ideated the stress-relieving function and engineer $\mathrm{E}$ ideated the initial system design. At experiment and evaluation processes stages, they detected the volume and weight related problems of the output devices and the inefficiency of the sensor's heartbeat measurement. To fix the issue, the engineer researched a different air-pumping device and replaced the old one, but the designer suggested the mechanism design for the output device module during the group tutorial with the instructor. In addition, to improve the efficiency of sensing data, the engineer suggested wearing the sensor like a watch.

Fourth, team G, self-EMS vest: designer G ideated the emergency medical function, and engineer $\mathrm{G}$ supported investigation of the operation principle of the respirator. The designer had initially ideated an automatic operation system, but the engineer suggested a manual control method due to reliability and miss-operation of sensor-controlled input-systems, as the function was focused on medical use and had to be reliable and stable.

Through these CFPD practices, a meaningful tendency for the possibility of cooperation between the participants was observed and discovered.

As shown in the case of team D's cooperation, if there was greater expandability of the potential of the selected technology than the designer's expectation, the engineer shared their expertise with the designer to introduce greater possible use of the technology which could generate further synergy in the convergence. This can be understood as the students' roles in theinitial ideation period were balanced to fuse the designer's idea and the engineer's expertise to promote their project on to further stages.

On the other hand, as in the taser-coat case, it was found that overall tasks of the R\&D process would be promoted by engineers, if the designer's ideated $R \& D$ concept, especially functionality, required too high a level of expertise in engineering. It could cause a negative convergence practice that designers just passively follow engineers' processes, designing and adjusting fashion platforms only depending on the engineers' developed systems. However, in this study's practice, with the instructor's intervention, the designer investigated and selected the spec for electronic components needed for functionality, locations, and means of the system installation in order to increase knowledge and meaningful experience of convergence cooperation. This was an educational action aimed at minimizing the effects of the reduction of the designer's role and achieving a more balanced convergence practice in Design education.

When it was understood that the initially selected devices were inappropriate for use, the different tendencies in problem management between designers and engineers were detected. For instance, in the cases of aroma therapy wear and self-EMS vest, the engineers tended to find more suitable devices to solve problems. On the other hand, designers tried to design alternative operating mechanisms or additional structures using more accessible technology to ameliorate the problem 
as well as the limitation of accessible technologies. These cases' tendency for problem solving can be understood as one of the positive directions of CFPD practices where designers can achieve their ultimate goal of the development of convergence fashion products. Designers can provide alternative operation principles or structures using basic technologies through in-depth research on the mechanism or operation principles of electronic components themselves, with minimal engineering support.

Therefore, through $\mathrm{R} \& \mathrm{D}$ practices using basic technologies, interacting with engineers, providing instructors' guidance to promote balanced ideation between design and engineering perspectives, and forcing in-depth process tasking, it can be expected that fashion majors' sense of difference or aversion to applying electronics to fashion design can be neutralized. Their knowledge and skill of electronic engineering can be improved to achieve convergence practices through the stepwise experience of $R \& D$ practices, with the level of technologies adapted in the practices gradually upgraded, step by step, according to the students' abilities.

\section{Conclusions}

This study aimed to investigate CFPD for fashion design education. Through the two experimental workshops explore practice methods, there were two findings as stated below:

First, the convergence of fashion and technology was pursued in the primary study to achieve technical expression of the designers' aesthetic perspectives. In contrast, the second workshop sought a way for convergence to provide particular functions for targeted users through reflection of the learning outcomes from the interactive co-investigations conducted by both typesof students. There seemed to be a characteristic effect of IDP reflected in the refined practice model, since the initial stage of ideation in IDP focuses on the specific needs of certain users and problems of existing products, and the conceptual tasks of the DC are supported in the students' thinking processes.

Second, there was a difference between the primary and refined workshops in terms of the cooperation tendencies of the students. In the primary study, designers and engineers elaborated the prototype design and system continually in playing their given separate roles, but exchange of knowledge and techniques among the developers was insufficient. In contrast, in the refined workshop, designers actively learned from engineers about the mechanisms of applicable technologies to develop their functional ideas and designed the operation principles of the output devices of the systems. Since engineers had to suggest applicable technologies and develop a system securing functionality as suggested by the designers, they tried to comprehend the designers' intentions. Both types of students tried to combine design thinking and engineering thinking to exceed the limitations of the operating mechanisms of available technologies, which implied a greater tendency towards cooperation.

For R\&D of CFPD in the field of fashion education, if the experience of sharing the specialties of the majors can be accrued step by step, the difficulties inherent in today's academic environment could be supplemented to prepare designers who have sufficient potential to deal with the convergence trends in current industries.

This study mainly focused on refining the methods of CFPD practice to develop products that could utilize the limited design budget of an education institution. The workshops were conducted with only a limited number of participants. Thus, it is a limitation of this study that the effectiveness of the methodologies could not be verified through practices with a larger number of students. Thus, there are further research plans for a cooperative R\&D project to be organized within the regular fashion design class to verify the effectiveness of this study's convergence 
practice methodology with the usual number of students. In addition, a more expansive cooperative $\mathrm{R} \& \mathrm{D}$ exercise with diverse engineering majors, especially advanced materials engineering, will be pursued for convergence fashion that creates more traditional clothing with multi-technological applications in a wide range of engineering areas. Also, it would be worthwhile for design students to broaden their knowledge and skills on how to construct fashion items as technology platforms and how to apply technological components in their designs.

Finally, it is hoped that the processes and findings of this study are utilized as a basis for the development of convergence fashion design processes and practice programs in cooperation with experts in engineering areas, particularly at a design school that has difficulty in providing students with engineering related education, which is the major thrust of this study.

\section{ACKNOWLEDGEMENTS}

This work was supported by the National Research Foundation of Korea(NRF) Grant funded by the KoreanGovernment(MSIP)(No. Grant Number - 2015R1A5A7037615)

\section{REFERENCES}

[1] Yoon, S. I., \& Kang, H. S. (2013). The Type and Development of Hybrid fashion's Convergence Focused on convergence of $21^{\text {st }}$ century technology and design. Design Forum, Society of Korea Design Trend, 38, 299-308.

[2] Quiin, B. (2002). Techno Fashion. Oxford: Berg.

[3] San Martin, M. (2010). Future Fashion: Innovative Material and Technology. Palermo: Promopress.

[4] Myint, C. Z., Barsoum, N., \& Ing, W. K. (2010). Design a Wearable Device for Blood Oxygen Concentration and Temporal Heart Beat Rate. AIP Conference Proceedings Series, 1239, 213-219.

[5] McCrindle, R. J., Williams, V. M., Victor, C. R., Harvey, A. P., Nyman, S. R., Barrett, J., Hogarth, H., Levene, P., Smith, R., \&Panek, P. (2011). Wearable Device to Assist Independent Living. International Journal on Disability and Human Development, 10(4), 349-354.

[6] Lee, S. (2004). Fashioning theFuture: Tomorrow's Wardrobe. New York: Thames \& Hudson.

[7] Sarah E., Braddock C., \& Marie O, (2007). TechnoTextile2: Revolutionary Fabrics for Fashion and Design: Bk. 2. New York: Thames \& Hudson.

[8] Sabine, S. (2008) Fashionable Technology: the Intersection of design, Fashion, Science, and Technology. New York: SpringerWien.

[9] Gepperth, J. (2012). Smart Things: Wearables \& Clothing. Advances in Media Technology, Technische Universität München Institute for Media Technology, München, ISSN 2191-8015, 4148.

[10] Alhumaid, K. (2020). The use of mobile technology for teaching and learning. International Journal of Education, 5(1), 1-18.

[11] Dunne, L. (2010). Smart Clothing in Practice: Key Design Barriers to Commercialization. Fashion Practice, 2(1), 41-66. DOI: 10.2752/175693810X12640026716393.

[12] Cross, N. (2000). Engineering Design Method: Stategies for Product Design (3th ed). Chichester: John Wiley \& Sons.

[13] Dieffenbacher, F. (2013). Fashion Thinking: Creative Approaches to the Design Process. New York: AVA.

[14] Ertas, A. (1996). The engineering design process (2nd ed.). New York: John Wiley \& Sons. 
[15] Rau, E. P. (2000). The Adoption of Operation Research in the United State during World War II. System, Expert, and Computers: The System Approach in Management and Engineering, World War II and After, https//:DOI: 10.7551/mitpress/978026208285 3.001.0001

[16] Park, H. C. (2006). A Study on a Historical Context of the Design Methodology Movement with an Emphasis on its Relations to Cyborg Sciences. Journal of Korean Society of Design Science, 19 (5), 105-118.

[17] Kim, K. H. (2007). A Study on the Development of Design Process Model Converging 4C and 4P of Design Marketing. Doctoral Thesis, Kyunghee University, Seoul.

[18] Roozenburg, N. F. M., \& Cross, N. G. (1991). Models of The Design: Integrating across the Disciplines. Design Studies, 12 (4), 212-220.

[19] Shin, J. H. (1997). A Study on Design Process with Flexibility for Product Development. Master Thesis, KoreaAdvancedInstituteofScienceandTechnology, Daejeon.

[20] Kim, E. (1995). A Study on the information system for integrated product design process: with emphasis on interface process between design and manufacturing. Master Thesis,KoreaAdvancedInstituteofScienceandTechnology, Daejeon.

[21] Seo, J. H. (1995). A Story on User Participatory Process on Product Design. Master Thesis, KoreaAdvancedInstituteofScienceandTechnology, Daejeon.

[22] Regan, C. L., Kincade, D. H., \& Sheldon G. (1998). Applicability of the Engineering Design Process Theory in the Apparel Design Process. Clothing and Textiles Research Journal, 16(1), 646.

[23] Ramirez, S. A. (2014). Slow Fashion: Developing a Conceptual Apparel Design Process. Master Thesis, Louisiana State University, Baton Rouge.

[24] Dimant, E. (2010). Minimalism and Fashion: Reduction in the PostModern Era. NewYork: Collins Design.

[25] Davis, M. L. (1980). Visual Design in Dress. London: Prentice-Hall International.

[26] Watkins, S. M. (1988). Using the Design Process to Teach Functional Apparel Design. Clothing and Textile Research Journal, 7 (1), 10-14.

[27] Lamb, J. M., \&Kallal, M. J. (1992). A Conceptual Framework for Apparel Design. Clothing and Textile Research Journal, 10 (2), 42-47.

[28] Lee, Y. K., \& Delong, M. (2016). Improving Creative Design Skills-The Effects of Past Experiences on Apparel Design Education-, Journal of the Korean Society of Clothing and Textiles, 40 (2), 397-408.

[29] McKelvey, K., \& Munslow, J. (2003). Fashion Design: Process, Innovation \&Practice. Oxford, UK: Wiley-Blackwell.

[30] Saffer, D. (2012). Designing for interaction: creating innovative applications and devices $\left(2^{\text {nd }}\right.$ ed). Berkeley: New riders.

[31] Fallman, D. (2003). Design-oreiented human-computer interaction. Designing Design, 5(1), 225232.

[32] Huang, K. Y. (2009). Challenges in human-computer interaction design for mobile devices. Proceedings of the World Congress on Engineering and Computer Science 2009 Vol. 1, Oct. 2009. San Francisco, USA: WCECS 2009, 1-6.

[33] Preece, J., Rogers, Y., and Sharp. (2015). Interaction Design: beyond Human-Computer Interaction (4h ed). Chichester; John Wiley \& Sons. 


\section{AUTHORS}

Hyunseung Lee. Research Professor, Modular Fashion Platform Research Centre, Kookmin university, Seoul, Republic of Korea (South). Ph.D. Dept. of Fashion Design, Graduation School of Techno Design, Kookmin university, Seoul, Republic of Korea (South). MA. Applied Imagination in the Creative Industries, Central Saint Martins College of Art and Design, UAL, London, UK. BA. Dept. of Fashion Design, Graduation School of Techno Design, Kookmin university, Seoul, Republic of Korea (South).

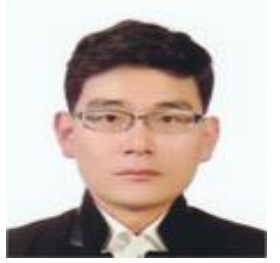

